\title{
Study of Thio-benzil Hydrogen Abstracting Photoinitiating System
}

\author{
Hong-Ru Li \\ Institute of Photographic Chemistry, Chinese Academy of Sciences, Beijing 100101, China \\ Jiang-Nan Gu, Shang-Xian Yu \\ Beijing Normal University, Chemical Department, 100875, Beijing, China
}

\begin{abstract}
Benzil derivatives and aliphatic tertiary amine were synthesized through new route. The photo-sensitivities of binary photoinitiating systems composed of the benzil derivatives and tertiary amine were measured and compared with commerciallized photoinitiators in the resist screenings. Sulfo-benzil derivatives were more reactive than the other compounds. The new aliphatic tertiary amine synthesized was more reactive than NMDEA (N-methyl diethanol amine).
\end{abstract}

Keywords: photoinitiator, photoimaging, hydrogen abstracting

\section{Introduction}

The photochemical cross-linking of acrylated coatings by UV or visible light has become established technology for many industrial applications, including offset lithographic inks, flexographic inks, screening printing, metal decoration, basecoats for beverage cans, wood coatings, pigmented coatings for textile applications, coatings exhibiting a steroscopic pattern, pigmented primary and secondary optical fibre coatings. Photoinitiator as an important chemical additive is used widely in these fields.[1,2] Many reactive monomers and efficient photoinitiators have been synthesized and are commercially available. However, improved photoinitiator system that exhibits faster curing speed and better photosensitivity is required. Up to now, there are two sorts of photoinitiators - free radical and cationic photoinitiators. In general, initiator free radicals are photogenerated by (1) Intramolecular bond cleavage, notably of aryl or alkyl ketones. Type I photoinitiators undergo a direct photofragmentation process ( $\alpha$ or less common $\beta$ cleavage) upon absorption of light and formation of initiating radicals capable of inducing polymerization. (2) Intermolecular $\mathrm{H}$-abstraction from H-donor, notably by diaryl ketones. Type II photoinitiators undergo a primary process of hydrogen atom abstraction from the environment. which may be the resin itself or a solvent. but usually a tertiary amine co-synergist is used for enhanced efficiency. $\alpha$-diketones were tested as acceptor components in an acrylic overprint varnish formulation containing an amine as hydrogen donor and an alpha-cleavage photoinitiator. [3] Benzil functions as a Type II 
photoinitiator by $\mathrm{H}$-abstraction from tertiary amines and is not so effective in the absence of $\mathrm{H}$ donors, because the low excitation energy of benzil (about $224 \mathrm{~kJ} \cdot \mathrm{mol}^{-1}$ ) can not overcome the CO-CO bond energy easily.[4] Bond scission also dominates the reaction of benzil under two photolaser-jet irradiation and benzoyl radicals are produced.[5,6] Tertiary amine as a typical hydrogen donor has strong affinity with triplet benzil.[7] The hydrogen abstraction reactions occurred in 1,2-diketone and related species are seen to affect in the use of optically active inclusion complexes. It is reported that benzoyl radical fragments participate in the initiation process and alkoxybenzoyl radical fragments participate in the termination.[8] Thus it is important to construct a molecule which can easily generate benzoyl radicals in the presence of tertiary amines on irradiation. In this work, a new aliphatic tertiary amine and the benzil derivatives were synthesized, and their co-initiating effect with the new tertiary amine were studied and compared with commerciallized compounds in the resist screenings.

\section{Experimental}

\subsection{Materials}

Oxalyl chloride, anhydrous aluminium trichloride, methyl toluidine and chlorbenzene were purchased from Beijing Chemical Agent Corporation. Diphenyl sulfide was gift from Professor David Leppard, Ciba-Geigy Company.

\subsection{Equipment}

DMS-300 UV spectrometer from Hitachi Corp., ORG UV Irradiation Meter, SYYA Plateingmaker, MO61 / 5KW / 30cm steps hardened meter.

\subsection{Measurement of Sensitivity}

The photosensitivity $\left(\mathrm{E}, \mathrm{mJ} \cdot \mathrm{cm}^{-2}\right)$ was determined by exposing the photosensitive layer through a 21-step tablet (Kodak No.2 step tablet) with high pressure mercury lamp in vacuum,[9] and photoinitiating reactivity was tested in the resist screenings.

\subsection{Synthesis}

C 1 (4, 4'-dichloro benzil), C 2 (4. $4^{\circ}$ dimethylamino benzil) and $\mathrm{C} 3\left(4,4^{\circ}\right.$ - bisphenyl thiobenzil), $\mathrm{C} 4 \mathrm{I}\left(\mathrm{HOCH}_{2} \mathrm{CH}_{2}\right)_{2} \mathrm{NCH}_{2} \mathrm{CH}_{2} \mathrm{CON}$ $\left.\left(\mathrm{CH}_{2} \mathrm{CH}_{2} \mathrm{OH}\right)_{2}\right]$ were synthesized from oxalyl chloride and mono-substituted benzene in the catalysis of anhydrous $\mathrm{AlCl}_{3}$. C 4 was synthesized through Michael reaction and further ammonolysis dealcoholation reaction.

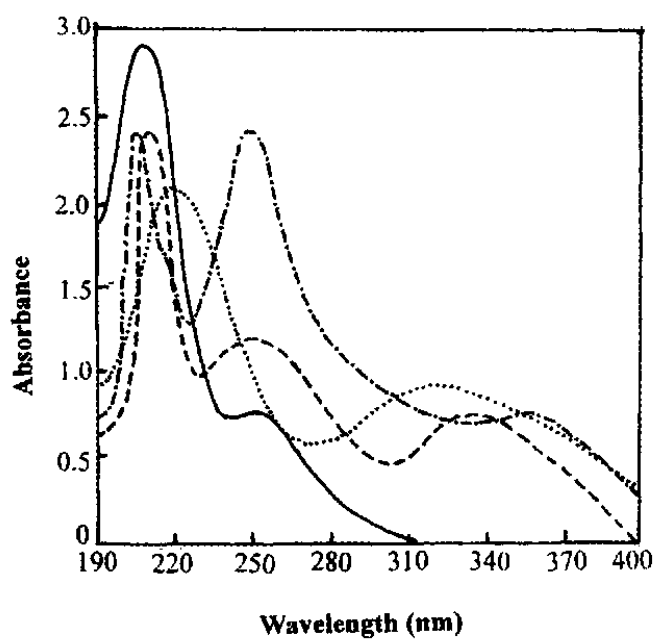

Fig. 1 UV spectra of C $1(--)$, C $2(\cdots)$. C $3(-\cdots)$ and benzil (-)

\section{Results and Discussion}

\subsection{Absorption spectra}

The absorption of benzil was mainly in the range of $200-300 \mathrm{~nm}$ for the strong $\pi \rightarrow \pi^{*}$ transition, and there was weak absorption for $\mathrm{n} \rightarrow$ $\pi^{*}$ at $\lambda>300 \mathrm{~nm}$. The spectra response range was extended while substituent groups $\left(-\mathrm{Cl} .-\mathrm{N}\left(\mathrm{CH}_{3}\right)_{2}\right.$ and $-\mathrm{SPh}$ ) were introduced into benzil. Compared with benzil, the $\mathrm{n} \rightarrow \pi^{*}$ transition in benzil derivatives were improved, and the absorption extended to $400 \mathrm{~nm}$. The UV spectra of C 1, C 2 . C 3 and benzil were in Fig. 1. It showed that the introduction of electron donating groups could extend the spectra response range, and the 
absorption red shifted to $400 \mathrm{~nm}$. There existed photoinduced electron transfer from substituent group to carbonyl group, and thus it has strong absorption at $400 \mathrm{~nm}$. In polar solvents, the red shift was more obvious than that in nonpolar

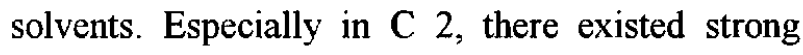
photo-induced electron transfer from dimethylamino to carbonyl group, and so it has the strongest absorption at $400 \mathrm{~nm}$ among these three compounds. Fig. 2 was the absorption spectra of $\mathrm{C} \quad \mathrm{l}$ at different time during irradiation. The absorption at $350 \mathrm{~nm}$ gradually disappeared with the increase of the irradiation time. The photobleaching appeared in the process of irradiation benefit to the deep curing.

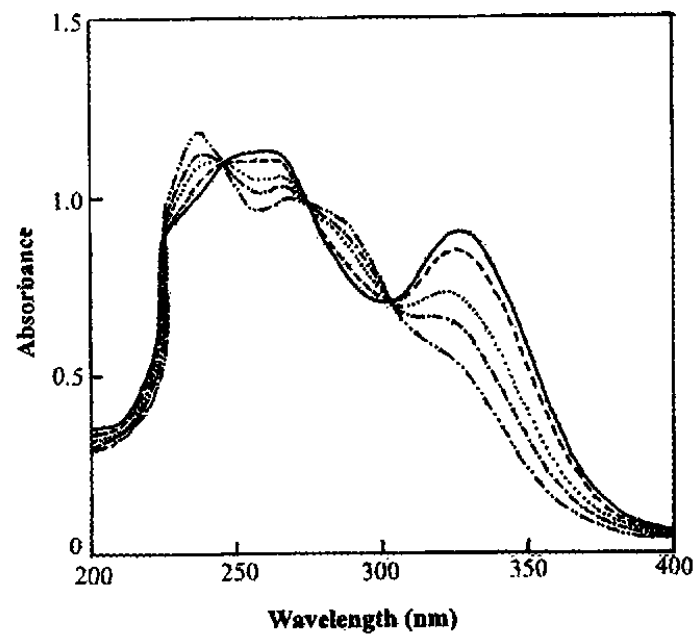

Fig.2 The changes of UV-visible absorption of $\mathrm{C}$ I with irradiation time. $\lambda=320-400 \mathrm{~nm}, \mathrm{t}=0 \mathrm{~min}(-)$;

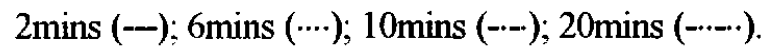

\subsection{Photoinitiating effect}

In the presence of tertiary amine, benzil functioned as a Type II photoinitiator by $\mathrm{H}$ abstraction from tertiary amines rather than as a Type I photoinitiator by intramolecular photocleavage of benzil. These results were intuitively reasonable in view of the low excitation energy of benzil (about $224 \mathrm{~kJ} \cdot \mathrm{mol}^{-1}$ ), which was insufficient for overcoming the $\mathrm{CO}-\mathrm{CO}$ bond energy (estimated at $>270 \mathrm{~kJ} \cdot \mathrm{mol}^{-1}$ ). However, in some conditions, benzil derivatives have been shown to undergo facile photolysis. Aromatic diketones as hydrogen abstracting photoinitiator, its excited triplet state $\left(T_{1}\right)$ abstracted hydrogen from a hydrogen-donor molecule $(\mathrm{RH})$ by the following mechanism (Scheme 1). The benzil ketyl radical could be trapped with spin trap nitrosocompounds and characterized by ESR spectroscopy.[10-12]

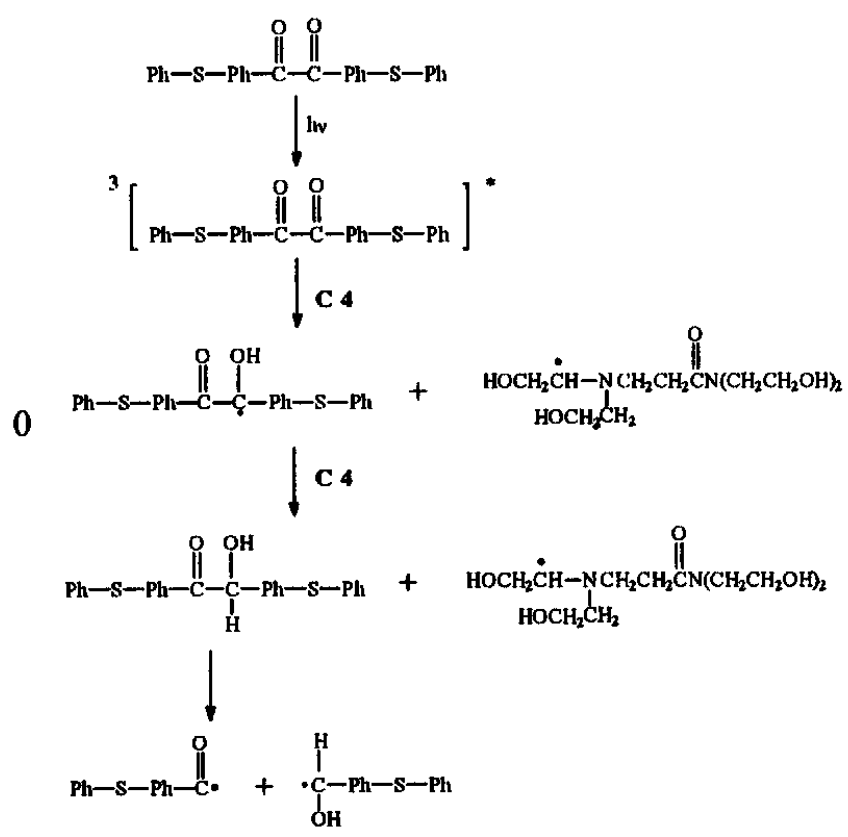

Scheme 1

Table 1. The photographic sensitivities of benzils photoinitiating system

\begin{tabular}{ccc}
\hline $\begin{array}{c}\text { Photoinitiating } \\
\text { systems }\end{array}$ & $\begin{array}{c}\text { Residual } \\
\text { Step(n) }\end{array}$ & $\begin{array}{c}\text { Photosensitivity } \\
\left(\mathrm{mJ} / \mathrm{cm}^{2}\right)\end{array}$ \\
\hline C 1 & 0 & $/$ \\
C 1 + C 4 & 7 & 16.8 \\
C 2 & $0 \sim 1$ & 133.8 \\
C 2 + C 4 & 5 & 33.6 \\
C 3 & 0 & $/$ \\
C 3 + C 4 & 11 & 4.2 \\
Benzil & 0 & $/$ \\
Benzil + C 4 & 2 & 94.7 \\
\hline
\end{tabular}

Vinyl monomers effectively quench the excited triplet-state of benzil and the rate of 
was low. The excited triplet-state of benzil forms, with tertiary amine, an exciplex that was further converted to benzil ketyl radical and amine radical, which might initiate polymerization of methyl methacrylate.

Three benzil derivatives having extended spectra response to $400 \mathrm{~nm}$, and a new aliphatic tertiary amine were synthesized. The photoinitiating effects of the binary systems composed of benzil derivatives and tertiary amine listed in Table 1. Though the absorption of benzil derivatives matched well with high pressure mercury lamp, it was not easy to undergo facile photolysis to initiate the monomer polymerization. The initiating effect of the photoinitiating system that only included C 1 or C 3 could not be tested, while the initiating effect of the system composed of $\mathrm{C} 2$ was tested. It may be ascribed to its stronger intra-molecular photoinduced electron transfer from dimethyl amino to carbonyl groups. While if tertiary amine was added into the systems, their residual steps increased dramatically. C 3's coinitiating effect was much better than $\mathrm{C} 1$ and $\mathrm{C} 2$. Moreover, the benzil derivatives' photoinitiating effects were better than benzil's. The introduction of substituent groups not only made the absorption red shift to $400 \mathrm{~nm}$ but also enhanced the absorption intensity. So under irradiation they could absorb near UV light efficiently, and excited triplet states of benzil derivatives could be formed easily. In the presence of tertiary amine, more free radicals were formed to initiate the polymerization, the photosensitivity could be improved remarkably.

As compared with the commercial photoinitiators, C 3 showed some photoinitiating reactivity, and the results were line with those

Table 2. Results on benzil derivatives in combination with different amines in the resist screening.

\begin{tabular}{|c|c|c|c|c|c|c|c|}
\hline \multirow{2}{*}{ Initiator } & \multirow{2}{*}{ Coinitiator } & \multirow{2}{*}{$\begin{array}{l}\text { Conc. } \\
\text { PI }(\%)\end{array}$} & \multirow{2}{*}{$\begin{array}{l}\text { Conc. } \\
\text { PI(\%) }\end{array}$} & \multirow{2}{*}{$\begin{array}{l}\text { Sol. } \\
\text { lh RT }\end{array}$} & \multicolumn{3}{|c|}{$\begin{array}{l}\text { MO61 / } 5 \mathrm{kw} / 30 \mathrm{~cm} \\
\text { Steps hardened }\end{array}$} \\
\hline & & & & & $10 "$ & $20 "$ & $40 "$ \\
\hline Irg. 907 & & 2 & & + & 9 & 12 & 14 \\
\hline Irg. 369 & & 2 & & + & 15 & 17 & 19 \\
\hline $\begin{array}{l}\text { Michler's } \\
\text { ketone }\end{array}$ & & 2 & & + & 6 & 8 & 10 \\
\hline $\begin{array}{l}\text { Michler's } \\
\text { ketone }\end{array}$ & NMDEA & 2 & 2 & + & 5 & 7 & 9 \\
\hline $\begin{array}{l}\text { Michler's } \\
\text { ketone }\end{array}$ & $\mathrm{C} 4$ & 2 & 2 & + & 6 & 8 & 10 \\
\hline Quant-BMS & & 2 & & + & 3 & 6 & 9 \\
\hline Quant-BMS & NMDEA & 2 & 2 & + & 6 & 8 & 10 \\
\hline Quant-BMS & C 4 & 2 & 2 & + & 6 & 8 & 10 \\
\hline C 3 & & 2 & & + & 4 & 7 & 10 \\
\hline C 3 & NMDEA & 2 & 2 & + & 7 & 9 & 11 \\
\hline C 3 & C 4 & 2 & 2 & + & 9 & 12 & 13 \\
\hline
\end{tabular}


shown in Table 1. (in Table 2, 10", 20" and 40" means that how many the residual steps were obtained after the systems were irradiated for $10 \mathrm{~s}$, $20 \mathrm{~s}$ and $40 \mathrm{~s}$ ). The photoiniating reactivity of system composed of $\mathrm{C} 3$ and NMDEA was a little better than that of system composed of MK and NMDEA, and the sensitivity of system composed C 3 and C 4 was almost the same as that of Irg. 907 Though $\mathrm{C} 2$ has the same spectra response range as $\mathrm{C} 3$, the co-initiating efficiency of $\mathrm{C} 2$ was much poorer than that of $\mathrm{C} 3$. It showed that thiophenyl substituent group could not only extend benzil's spectra response range, but also enhance the hydrogen abstracting affinity, thus more free radicals could be produced to initiate monomer polymerization. Compared with $\mathrm{C} 2, \mathrm{C} 3$ has weak $\mathrm{C}-\mathrm{S}$ bond, and free radical could be produced to initiate polymerization through the scission of C-S bond. It was reported that $\mathrm{PhS}$ - had initiating effect at low concentration.[13] While it is deserved to note that if its is in high concentration, termination of the chain by this radical started to play an important role in the polymerization process. From

Acknowledgement Thanks for the financial support of Ciba-Geigy Company.

\section{References}

1. K. K. Dietliker, Chem. \& Tech. Of $U V \& E B$ Formu. Coat., Inks \& Paints 3 (1991) 168.

2. D. O. Cowan, R. L. Drisko, Elem. of Org. Photochem., New York, Plenum Press 75 (1976).

3. K. K. Dietliker, Chem. \& Tech. Of $U V \& E B$ Formu. Coat., Inks \& Paints 3 (1991) 266.

4. S. Peter Pappas, Handbook of Org. Photochem. II 329 (1982).

5. W. Adam, R. S. Oestrich, J. Am. Chem. Soc. 115 (1993) 3455.

6. W. G. McGimpsey, J. C. Scaiano, J. Am. Chem. Soc. 101 (1979) 7740.

7. N. J. Turro, Modern Molecular Photochem.
Table 2, it also could be seen that $\mathrm{C} 4$ was clearly the more reactive amine and was about twice as reactive as NMDEA. Meanwhile, it can be used not only in aqueous system, but also in nonaqueous system, and it has an excellent therrmostability and less yellowness.[14] As a new aliphatic tertiary amine coinitiator, C 4 could improve the sensitivity dramatically and reduce oxygen inhibition. So the curing effect was fine after it was added into the initiating system.

\section{Conclusion}

Three compounds synthesized in new route have obvious absorption in the near UV light region. and it matches well with high pressure mercury light lamp. C 3 was more reactive than all the other synthesized compounds. C 4 was clearly the reactive amine and was about twice as reactive than NMDEA. In the synergy effect of tertiary amine (C 4), the speed of photoreaction was increased dramatically, and thus it initiated the polymerization of MMA monomers efficiently, the high photosensitivity was obtained.

383 (1978).

8. H. J. Hageman, F. P. B. Van der Maeden and P.

C. G. Janssen, Macromol. Chem. 180 (1979) 2531.

9. S. Yu, J. Japan. Chem. Soc. 7 (1983) 975.

10. H. Fischer, R. Baer, R. Hany, I. Verholen, M. Walbiner, J. Chem. Soc., Perkin Trans 2(1990) 787.

11. T. Ikoma, K. Akiyama, S. Tero-Kubota. Y. Ikegami, Chem. Lett. 1491 (1990).

12. P. J. Krusic, T. A. Rettig, J. Am. Chem. Soc. 92 (1970) 722.

13. H. Tomioka, Y. Takimoto. M. Kawabata. M. Harada, J. Photochem. Photobio.. A. Chem. 53 (1990) 359.

14. H. R. Li, S. X. Yu, J. N. Gu, New Aliphatic Tertiary Amine used as Photoaccelerators, 2nd Asia Photochem. Confer. Pro. (1996). 